\title{
Detection of mercury ions using silver telluride nanoparticles as a substrate and recognition element through surface-enhanced Raman scattering
}

\author{
Chia-Wei Wang, Zong-Hong Lin, Prathik Roy and Huan-Tsung Chang*
}

Department of Chemistry, National Taiwan University, Taipei, Taiwan

\section{Edited by:}

Shusheng Zhang, Qingdao

University of Science and

Technology, Linyi University, China

Reviewed by:

Lingxin Chen, Chinese Academy of Sciences, China

Yingshu Guo, Linyi University, China

*Correspondence:

Huan-Tsung Chang, Department of Chemistry, National Taiwan

University, 1, Section 4, Roosevelt

Road, Taipei 106, Taiwan

e-mail: changht@ntu.edu.tw
In this paper we unveil a new sensing strategy for sensitive and selective detection of $\mathrm{Hg}^{2+}$ through surface-enhanced Raman scattering (SERS) using $\mathrm{Ag}_{2}$ Te nanoparticles (NPs) as a substrate and recognition element and rhodamine 6G (R6G) as a reporter. $\mathrm{Ag}_{2} \mathrm{Te}$ NPs prepared from tellurium dioxide and silver nitrate and hydrazine in aqueous solution containing sodium dodecyl sulfate at $90^{\circ} \mathrm{C}$ with an average size of $26.8 \pm 4.1 \mathrm{~nm}$ (100 counts) have strong SERS activity. The $\mathrm{Ag}_{2}$ Te substrate provides strong SERS signals of R6G with an enhancement factor of $3.6 \times 10^{5}$ at $1360 \mathrm{~cm}^{-1}$, which is comparable to Ag NPs. After interaction of $\mathrm{Ag}_{2} \mathrm{Te}$ NPs with $\mathrm{Hg}^{2+}$, some $\mathrm{HgTe}$ NPs are formed, leading to decreases in the SERS signal of R6G, mainly because HgTe NPs relative to $\mathrm{Ag}_{2} \mathrm{Te} N P s$ have weaker SERS activity. Under optimum conditions, this SERS approach using $\mathrm{Ag}_{2} \mathrm{Te}$ as substrates is selective for the detection of $\mathrm{Hg}^{2+}$, with a limit of detection of $3 \mathrm{nM}$ and linearity over 10-150 $\mathrm{nM}$. The practicality of this approach has been validated for the determination of the concentrations of spiked $\mathrm{Hg}^{2+}$ in a pond water sample.

Keywords: surface-enhanced Raman scattering, nanoparticles, silver telluride, mercury telluride, mercury ions

\section{INTRODUCTION}

Monitoring the level of mercury ions in ecological systems is an extremely important issue, mainly because they are highly toxic, non-biodegradable, and bioaccumulated (Zahir et al., 2005; Clarkson et al., 2008). Several techniques such as atomic absorption/emission spectrometry, atomic fluorescence spectrometry, inductively coupled plasma spectrometry (ICP-MS) have been applied to detect $\mathrm{Hg}^{2+}$ in environmental and biological samples (Leermakers et al., 2005; Butler et al., 2006; Li et al., 2006). Among them, ICP-MS provides the highest sensitivity and a widest linear range, but the system is expensive because it requires expensive noble gas. In addition, it is not easy for the in-field analysis.

With advantages of simplicity, low cost, sensitivity, and selectivity, a number of optical and electrochemical sensors have been demonstrated for the detection of $\mathrm{Hg}^{2+}$ (Huang and Chang, 2007; Darbha et al., 2008; Jena and Raj, 2008; Zhu et al., 2009). Having extremely high stability, specificity, and ease in preparation, DNA-based optical sensors have become popular for the detection of $\mathrm{Hg}^{2+}$ (Chiang et al., 2008; Stewart et al., 2008; Dave et al., 2010). Polythymines $\left(T_{n}\right)$ that are specific toward $\mathrm{Hg}^{2+}$ ions through $\mathrm{T}-\mathrm{Hg}^{2+}-\mathrm{T}$ coordination have been used for the selective and sensitive detection of $\mathrm{Hg}^{2+}$ ions through fluorescence detection based on the analyte induced changes in the DNA conformation, leading to enhanced efficiency in the fluorescence resonance energy transfer between the donor and the acceptor or increased quantum yield of the fluorophore. In addition, $T_{n}$ conjugated with gold nanoparticles (NPs) have been used for the detection of $\mathrm{Hg}^{2+}$ ions through absorption or fluorescence modes (Huang et al., 2007; Lee et al., 2007; Wang et al., 2008; Xue et al., 2008). The detections are mainly based on the analyte induced changes in the DNA conformation and charge density on the surfaces of the Au NPs, leading to changes in absorbance (red shift upon aggregation) or fluorescence intensity (either decreases or increases). Surface-enhanced Raman scattering (SERS) using Ag NPs conjugated with $T_{n}$ and organic dyes (reporter) are alternative for the sensitive detection of $\mathrm{Hg}^{2+}$ (Wang et al., 2009, 2011). Upon interaction with $\mathrm{Hg}^{2+}$, the DNA conformation changes, leading to changes in the distance of the reporter from the surfaces of Ag NPs and thus changes in the SERS signal (Grubisha et al., 2003; Doering et al., 2007). Although these sensing systems are sensitive and suitable for in-field analysis, the DNA is expensive and their sensitivity and selectivity are highly dependent on the ionic strength of the samples, limiting their wide practicality.

Relative to normal Raman scattering, SERS can provide enhancement factors (EFs) up to $10^{15}$ theoretically through a long-range electromagnetic (EM) effect such as "hot spots," and/or chemical effect due to the charge-transfer excitation of chemisorbed molecules (Aravind et al., 1981; Kneipp et al., 1997; Nie and Emery, 1997). The EF values are dependent on the compositions, sizes, and shapes of the SERS substrates. Relative to spherical shaped silver NPs, silver plates and silver nanowires provides higher $\mathrm{EF}$ values; $\mathrm{EF}$ values up to $10^{8}$ have been demonstrated for the SERS signals of common reporters such as Rhodamine 6G (R6G), 4-mercaptobenzoic acid, and 5,5'dithiobis(2-nitrobenzoic acid) (Tao et al., 2003; Yang et al., 2007). Gold-tellurium nanodumbbells, gold-tellurium nanopeapods, and gold pearl-necklace nanomaterials (Au PNNs) providing EF values of R6G up to $5.6 \times 10^{9}$ have been used for the selective detection of human serum albumin down to 70 pM using AB 580 as a reporter (Lin and Chang, 2008; Lin et al., 2011). 
In this study, we developed a simple SERS approach using silver telluride $\left(\mathrm{Ag}_{2} \mathrm{Te}\right) \mathrm{NPs}$ as substrates for sensitive and selective detection of $\mathrm{Hg}^{2+}$ in aqueous solutions. $\mathrm{Ag}_{2} \mathrm{Te}$ NPs were prepared from tellurium dioxide and silver nitrate in the presence of hydrazine and sodium dodecyl sulfate (Samal and Pradeep, 2009). The $\mathrm{Ag}_{2} \mathrm{Te}$ NPs provided SERS enhancement effect of R6G. Upon increasing the concentration of $\mathrm{Hg}^{2+}$ ions, the SERS signal of R6G decreased. The novel SERS approach was further validated by the determination of the concentrations of $\mathrm{Hg}^{2+}$ in pond water samples, showing advantages of sensitivity, selectivity, and simplicity.

\section{MATERIALS AND METHODS CHEMICALS}

Hydrazine monohydrate $(80 \%)$ and tellurium dioxide powder (99.9\%) were purchased from SHOWA (Tokyo, Japan). Sodium phosphate monobasic, dibasic, and tribasic, and sodium dodecyl sulfate were purchased from Acros (Geel, Belgium). Mercury chloride, $\mathrm{R} 6 \mathrm{G}$, silver nitrate, and other metal salts $\left[\mathrm{Ca}^{2+}, \mathrm{Co}^{2+}\right.$, $\mathrm{Cu}^{2+}, \mathrm{Cd}^{2+}, \mathrm{K}^{+}, \mathrm{Mg}^{2+}, \mathrm{Mn}^{2+}, \mathrm{Ni}^{2+}, \mathrm{Cr}^{3+}, \mathrm{Fe}^{3+}, \mathrm{Fe}^{2+}, \mathrm{Pd}^{2+}$, $\mathrm{Zn}^{2+}, \mathrm{Pb}^{2+}$, and $\mathrm{Na}^{+}$(chlorides)] used in this study were purchased from Sigma Aldrich (Missouri, USA). Ultrapure water was obtained using a Milli-Q ultrapure $(18.2 \mathrm{M} \Omega-\mathrm{cm})$ system.

\section{SYNTHESIS OF $\mathrm{Ag}_{2} \mathrm{Te}$ NPS}

Hydrazine $(1 \mathrm{~mL})$ was added slowly to a sample vial containing aqueous solution $(9 \mathrm{~mL})$ of tellurium dioxide $(5 \mathrm{mM})$, silver nitrate $(10 \mathrm{mM})$, and sodium dodecyl sulfate $(30 \mathrm{mM})$. The mixture was then subjected to constant magnetic stirring at $90^{\circ} \mathrm{C}$. The solution changed color from colorless to dark brown after $8 \mathrm{~h}$, indicating the formation of $\mathrm{Ag}_{2} \mathrm{Te}$ NPs. To terminate the reaction and to remove most of the matrix (e.g., hydrazine), the $\mathrm{Ag}_{2} \mathrm{Te} \mathrm{NPs}$ were subjected to three cycles of centrifugation [relative centrifugation force (RCF): $12000 \mathrm{~g}$ for $10 \mathrm{~min}$ ] and wash $(3 \times 10 \mathrm{~mL}$ of water). For simplicity, the concentration of the as-prepared $\mathrm{Ag}_{2} \mathrm{Te}$ NPs in $10 \mathrm{~mL} \mathrm{H}_{2} \mathrm{O}$ is represented as $1 \mathrm{X}$.

\section{CHARACTERIZATION}

JEOL JSM-1230 and FEI Tecnai-G2-F20 transmission electron microscopes (TEM) were used to measure the sizes and shapes of the as-prepared $\mathrm{Ag}_{2} \mathrm{Te}$ NPs. The re-dispersed $\mathrm{Ag}_{2} \mathrm{Te}$ NPs were separately placed on formvar/carbon film Cu grids (200 mesh; Agar Scientific) and dried at ambient temperature $\left(25^{\circ} \mathrm{C}\right)$. An energy dispersive X-ray (EDAX) system (Inca Energy 200, Oxford) was used to determine the composition of the as-prepared NMs. Raman spectra were recorded using a Raman spectrometer (DongWoo 500i, Korea) equipped with a $50 \times$ objective and a charge-coupled detector. The excitation wavelength was $532 \mathrm{~nm}$ and the spectral aperture was $50 \mu \mathrm{m}$. The signal collection time for each sample was $30 \mathrm{~s}$.

\section{DETECTION OF $\mathrm{Hg}^{2+}$ IONS USING $\mathrm{Ag}_{2} \mathrm{Te}_{\mathrm{NPs}}$}

$\mathrm{Ag}_{2} \mathrm{Te}$ NPs $(0.01 \times, 100 \mu \mathrm{L})$, phosphate buffer $(\mathrm{PB})(1 \mathrm{mM}$, $\mathrm{pH} 4.0,100 \mu \mathrm{L})$, and SDS $(0.1 \mathrm{mM}, 100 \mu \mathrm{L})$ were added to aqueous solutions $(0.7 \mathrm{~mL})$ containing various concentrations of $\mathrm{HgCl}_{2}$ (final concentrations $10-150 \mathrm{nM}$ ). The mixtures were equilibrated under constant stirring at $37^{\circ} \mathrm{C}$ for
$10 \mathrm{~min}$. After centrifugation at $12000 \mathrm{~g}$ for $10 \mathrm{~min}$, the supernatants were discarded and the pellets were dispersed in R6G solution $(10 \mu \mathrm{M}, 20 \mu \mathrm{L})$. Finally, drops $(1 \mu \mathrm{L})$ of the R6G mixtures were added onto separate silica wafers and dried at ambient temperature $\left(25^{\circ} \mathrm{C}\right)$ prior to SERS measurement.

\section{ANALYSIS OF REAL SAMPLE}

Pond water sample was collected from the National Taiwan University campus, and subsequently filtered through a $0.45 \mu \mathrm{m}$ membrane. For comparison, aliquots $(0.1 \mathrm{~mL})$ of the pond water sample was mixed with $\mathrm{HNO}_{3}(0.9 \mathrm{~mL}$, final concentration $2 \%$ ) prior to ICP-MS analysis. Aliquots of the pond water $(100 \mu \mathrm{L})$ were spiked with standard solutions $(100 \mu \mathrm{L})$ containing $\mathrm{Hg}^{2+}$ at various concentrations $(0.3-1.5 \mu \mathrm{M})$. Next, PB $(1 \mathrm{mM}, \mathrm{pH} 4.0,100 \mu \mathrm{L})$, SDS $(0.1 \mathrm{mM}, 100 \mu \mathrm{L}), \mathrm{Ag}_{2} \mathrm{Te} \mathrm{NPs}$ $(0.01 \times, 100 \mu \mathrm{L})$, and water $(500 \mu \mathrm{L})$ were added to the mixture to give final volumes of $1 \mathrm{~mL}$. The mixtures were equilibrated under constant stirring at $37^{\circ} \mathrm{C}$ for $10 \mathrm{~min}$. After centrifugation at $12000 \mathrm{~g}$ for $10 \mathrm{~min}$, the supernatants were discarded and the pellets were dispersed in R6G solution $(10 \mu \mathrm{M}, 20 \mu \mathrm{L})$. Finally, drops of solutions $(1 \mu \mathrm{L})$ were added onto separate silica wafers and dried at ambient temperature prior to SERS measurement.

\section{RESULTS AND DISCUSSION SENSING STRATEgY}

Scheme 1 shows the detection of $\mathrm{Hg}^{2+}$ based on differential SERS EFs of $\mathrm{Ag}_{2} \mathrm{Te}$ and $\mathrm{HgTe} \mathrm{NPs}$. $\mathrm{Ag}_{2} \mathrm{Te}$ relative to $\mathrm{HgTe}$ provides a higher EF value. The displacement reaction between $\mathrm{Hg}^{2+}$ and $\mathrm{Ag}_{2} \mathrm{Te}$ NPs leads to the formation of HgTe nanostructures and decomposition of $\mathrm{Ag}_{2}$ Te NPs. As a result, the SERS signal of R6G decreases upon increasing the concentration of $\mathrm{Hg}^{2+}$, mainly because $\mathrm{Ag}_{2}$ Te relative to $\mathrm{HgTe}$ NPs provides a greater SERS EF value. Although the $K_{\mathrm{sp}}$ values of $\mathrm{Ag}_{2} \mathrm{Te}$ and $\mathrm{HgTe}$ are unavailable, the latter has a small one based on that of the metal selenides (Moon et al., 2010). For example, $\mathrm{Ag}_{2} \mathrm{Se}$ relative to $\mathrm{HgSe}$ has a higher $K_{\mathrm{sp}}$ value $\left(1 \times 10^{-54}\right.$ vs. $\left.4 \times 10^{-59}\right)$ (Wang et al., 2007). It

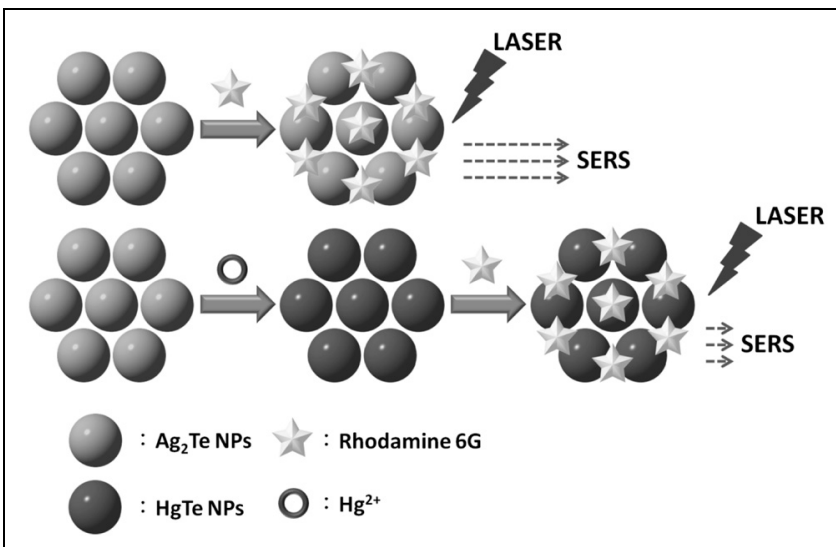

Scheme 1 | Schematic representation of the sensing of $\mathrm{Hg}^{2+}$ through SERS using $\mathrm{Ag}_{2} \mathrm{Te}$ NPs as a substrate and recognition element. 
has been reported that the reaction of $\mathrm{Ag}_{2} \mathrm{Te}$ nanostructures with $\mathrm{Hg}^{2+}$ ions is spontaneous and fast (Samal and Pradeep, 2011).

To confirm the formation of HgTe NPs from the reaction of $\mathrm{Ag}_{2} \mathrm{Te}$ NPs with $\mathrm{Hg}^{2+}$, we conducted TEM, EDX, and XRD measurements. Figure 1A shows the TEM image of as-prepared $\mathrm{Ag}_{2} \mathrm{Te}$ NPs with an average size of $26.8 \pm 4.1 \mathrm{~nm}$ (100 counts). On the other hand, the TEM image displayed in Figure 1B shows HgTe NPs with an average size of $37.7 \pm 6.8 \mathrm{~nm}$. Different morphologies in the two TEM images reveal the changes in the $\mathrm{Ag}_{2} \mathrm{Te}$ NPs. The EDX patterns (Figures 1C,D) confirm the displacement reaction between $\mathrm{Hg}^{2+}$ and $\mathrm{Ag}_{2} \mathrm{Te}$ NPs. The XRD patterns of $\mathrm{Ag}_{2} \mathrm{Te}$ NPs (Figure 1E) and its reaction product (Figure 1F) with $\mathrm{Hg}^{2+}$ agree with the literature data of $\mathrm{Ag}_{2} \mathrm{Te}$ (JCPDS: 34-0142) and HgTe (JCPDS: 75-2084), respectively.

The EF value of $\mathrm{Ag}_{2}$ Te NPs ( $0.1 \mathrm{X}$ ) was investigated using R6G as a reporter. The limits of detection (LODs) at a signal-to-noise $(\mathrm{S} / \mathrm{N}) 3$ for R6G using silica wafers and $\mathrm{Ag}_{2}$ Te NPs as SERS substrates were $1.8 \mathrm{mM}$ and $5 \mathrm{nM}$, respectively, which reveals that the $\mathrm{Ag}_{2} \mathrm{Te}$ substrate provided an EF value of $3.6 \times 10^{5}$. The EF value of $\mathrm{Ag}_{2} \mathrm{Te} \mathrm{NPs}$ is comparable with that of $\mathrm{Ag}$ NPs (Wang et al., 1980; Kerker, 1987). The SERS signal of R6G on the $\mathrm{Ag}_{2} \mathrm{Te}$ substrate was about 5-fold greater than that on an HgTe substrate that had been formed from the reaction of $\mathrm{Ag}_{2} \mathrm{Te}$ NPs with $100 \mathrm{nM}$ $\mathrm{Hg}^{2+}$ ions. The decreased SERS signal of R6G at a constant concentration $(10 \mu \mathrm{M})$ is related to the concentration of $\mathrm{Hg}^{2+}$ ions (to be discussed later), revealing the potential use of this approach for the determination of the concentration of $\mathrm{Hg}^{2+}$ ions. The

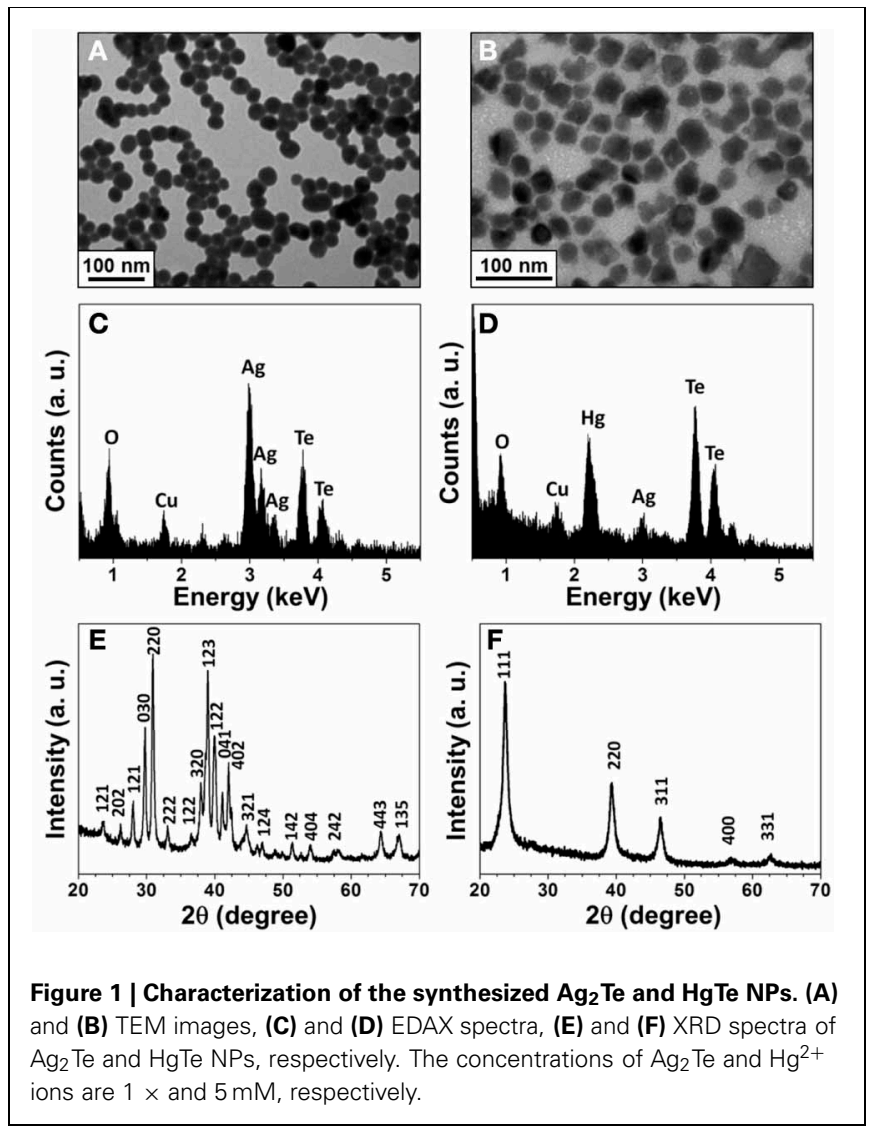

decrease in SERS signal was due to the decreased amount of $\mathrm{Ag}_{2} \mathrm{Te}$ NPs.

\section{OPTIMIZATION OF DETECTION CONDITIONS}

In order to optimize the sensing condition, we investigated several important parameters, including concentration of R6G, reaction time, and $\mathrm{pH}$. The strongest SERS signal of R6G at $1361 \mathrm{~cm}^{-1}$ (aromatic C-C stretching) was used to evaluate the effects of these parameters. Figure 2A shows that the SERS signal of R6G at $1361 \mathrm{~cm}^{-1}$ increased upon increasing its concentration, with a saturated concentration of $10 \mu \mathrm{M}$. Figure 2B displays the reaction was completed within 10 min when using $\mathrm{Hg}^{2+}$ at the concentration of $100 \mathrm{nM}$. Figure 2C displays that $\mathrm{pH}$ is not an important factor over the investigated $\mathrm{pH}$ range (4.0-10.0), mainly because the replacement reaction between $\mathrm{Ag}_{2} \mathrm{Te}$ and $\mathrm{Hg}^{2+}$ ions and the SERS signal of R6G are both not $\mathrm{pH}$ sensitive. Although larger $\mathrm{Ag}_{2} \mathrm{Te}$ NPs provided greater SERS EF values, poor reproducibility of SERS signals due to their instability in aqueous solution is problematic.

\section{SENSITIVITY AND SELECTIVITY OF $\mathbf{H g}^{2+}$ DETECTION}

Figure 3A shows that the SERS signal of R6G decreased upon increasing the $\mathrm{Hg}^{2+}$ concentration, with a linear relationship between the SERS ratios $\left(\left(I_{R 0}-I_{R}\right) / I_{R 0}\right)$ at $1361 \mathrm{~cm}^{-1}$ and the $\mathrm{Hg}^{2+}$ concentration ranging from 10 to $150 \mathrm{nM}\left(R^{2}=0.98\right)$. This

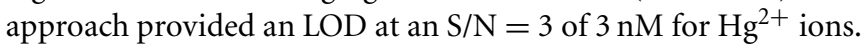
The sensitivity is better than that provided by SERS approaches using different reporters (Zamarion et al., 2008; Han et al., 2010; Senapati et al., 2011; Luo et al., 2012). Control experiments were carried out to test the specificity of the developed approach for $\mathrm{Hg}^{2+}$ ions $(100 \mathrm{nM})$ under optimal conditions in the presence of

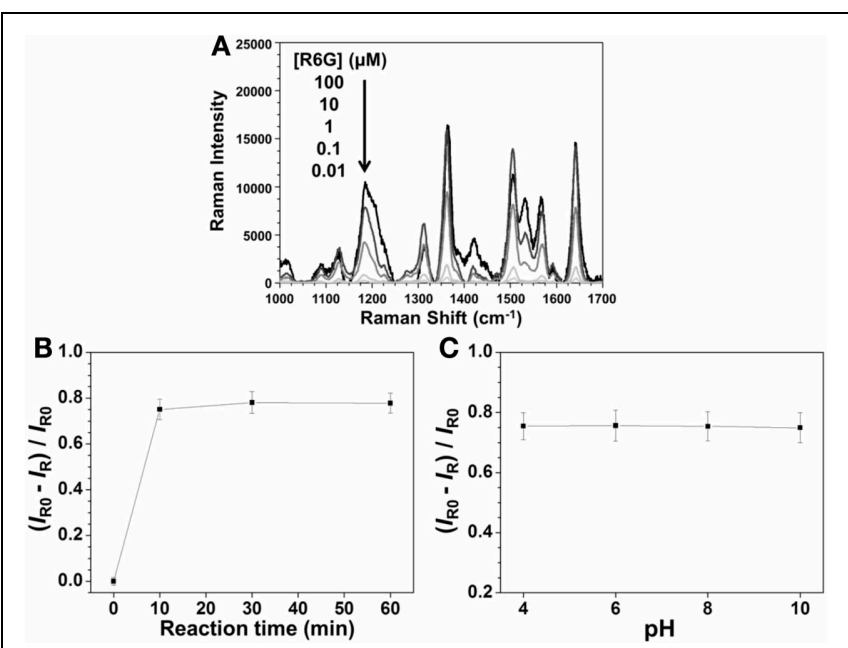

Figure 2 | Effects of (A) R6G concentration, (B) reaction times, and (C) $\mathrm{pH}$ on the SERS signal of R6G at $1361 \mathrm{~cm}^{-1}$ when using $\mathrm{Ag}_{2} \mathrm{Te} \mathrm{NPs}$ as a substrate. The concentrations of $\mathrm{Ag}_{2} \mathrm{Te}$ NPs were both $0.001 \times$ in (A) and $(\mathbf{B})$, of $\mathrm{Hg}^{2+}$ were 0 in $(\mathbf{A})$ and $100 \mathrm{nM}$ in (B) and (C), and of R6G were both $10 \mu \mathrm{M}$ in (B) and (C). The $\mathrm{pH}$ values were both 4.0 in (A) and (B) and reaction times were both $10 \mathrm{~min}$ in $(\mathbf{A})$ and $(\mathbf{C})$. $I_{R 0}$ and $I_{R}$ are the SERS intensities of R6G at $1361 \mathrm{~cm}^{-1}$ in the absence and presence of $\mathrm{Hg}^{2+}$ $(100 \mathrm{nM})$, respectively, in (B) and (C). 

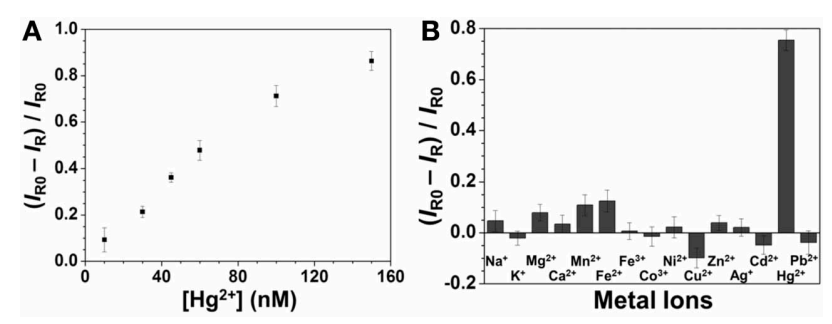

Figure 3 | (A) Sensitivity and (B) selectivity of the SERS approach for $\mathrm{Hg}^{2+}$. Concentrations: $100 \mathrm{nM}$ for $\mathrm{Hg}^{2+}$ and $1 \mu \mathrm{M}$ for the other metal ions. Reaction time was $10 \mathrm{~min}$ and $\mathrm{pH}$ value was 4.0. The other conditions are the same as in Figure 2.

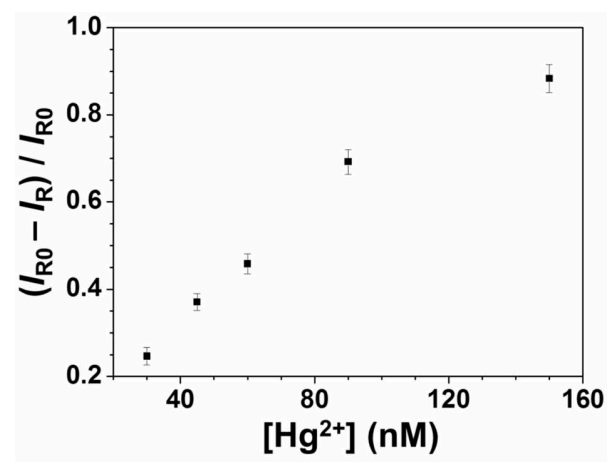

Figure 4 | Detection of $\mathrm{Hg}^{2+}$ in a spiked pond water sample through SERS using $\mathrm{Ag}_{2} \mathrm{Te}$ NPs as a substrate. Concentrations of $\mathrm{Hg}^{2+}$ ions ranged from 30 to $150 \mathrm{nM}$.

various metal ions (each at a concentration of $1 \mu \mathrm{M}$ ). The results displayed in Figure 3B reveal that the sensing approach is selective to $\mathrm{Hg}^{2+}$ ions. The potential interferences could not replace $\mathrm{Ag}^{+}$ions from the $\mathrm{Ag}_{2} \mathrm{Te}$ NPs, resulting in negligible changes in the SERS signal of R6G at $1361 \mathrm{~cm}^{-1}$.

\section{REFERENCES}

Aravind, P. K., Nitzan, A., and Metiu, H. (1981). The interaction between electromagnetic resonances and its role in spectroscopic studies of molecules adsorbed on colloidal particles or metal spheres. Surf. Sci. 110, 189-204. doi: 10.1016/00396028(81)90595-1

Butler, O. T., Cook, J. M., Harrington, C. F., Hills, S. J., Rieuwerts, J., and Miles, D. L. (2006). Atomic spectrometry update. Environmental analysis. J. Anal. At. Spectrom. 21, 217-243. doi: 10.1039/B516025C

Chiang, C.-K., Huang, C.-C., Liu, C.-W., and Chang, H. T. (2008). Oligonucleotide-based fluorescence probe for sensitive and selective detection of mercury(II) in aqueous solution. Anal. Chem. 80, 3716-3721. doi: 10.1021/ac800142k
Clarkson, T. W., Magos, L., and Myers, G. J. (2008). The toxicology of mercury-current exposures and clinical manifestations. N. Engl. J. Med. 349, 1731-1737. doi: 10.1056/NEJMra022471

Darbha, G. K., Singh, A. K., Rai, U. S., Yu, E., Yu, H., and Ray, P. C. (2008). Selective detection of mercury (II) ion using nonlinear optical properties of gold nanoparticles. J. Am. Chem. Soc. 130, 8038-8043. doi: 10.1021/ ja801412b

Dave, N., Chan, M. Y., Huang, P.-J. J., Smith, B. D., and Liu, J. (2010). Regenerable DNA-functionalized hydrogels for ultrasensitive, instrument-free mercury(II) detection and removal in water. J. Am. Chem. Soc. 132, 12668-12673. doi: $10.1021 /$ ja106098

\section{REAL SAMPLE ANALYSIS}

To examine the practicality of our approach, the concentration of $\mathrm{Hg}^{2+}$ in a pond water sample was determined. Our ICP-MS result showed that no $\mathrm{Hg}^{2+}$ was detected. By applying a standard addition method, the Raman ratios against the concentration of $\mathrm{Hg}^{2+}$ was found to be linear $\left(R^{2}=0.98\right)$ over $30-150 \mathrm{nM}$ (Figure 4). The recovery percentage values of $\mathrm{Hg}^{2+}$ over the concentration range $(30-150 \mathrm{nM})$ were $96-103 \%$, showing low matrix interference. Our results reveal that this approach holds great potential for the determination of the concentrations of $\mathrm{Hg}^{2+}$ in environmental samples.

\section{CONCLUSIONS}

We have demonstrated a SERS-based approach for the detection of $\mathrm{Hg}^{2+}$ ions using $\mathrm{Ag}_{2} \mathrm{Te}$ NPs as a substrate and recognition element and R6G as a reporter. To the best of our knowledge, this is the first example using a single material $\left(\mathrm{Ag}_{2} \mathrm{Te}\right)$ as the substrate and recognition element in SERS technology. Relative to $\mathrm{Ag}_{2} \mathrm{Te}$, HgTe is a less SERS active substrate, thus the SERS signals of R6G decreased upon increasing $\mathrm{Hg}^{2+}$ concentration when using $\mathrm{Ag}_{2} \mathrm{Te}$ NPs as a substrate. This novel approach is sensitive (LOD $3 \mathrm{nM}$ ) and selective for the detection of $\mathrm{Hg}^{2+}$ ions over a wide $\mathrm{pH}$ range. With its high sensitivity, selectivity, and simplicity, the SERS-based approach holds great potential for the determination of the concentrations of $\mathrm{Hg}^{2+}$ in environmental samples.

\section{AUTHOR CONTRIBUTIONS}

Chia-Wei Wang: He did the characterization of $\mathrm{Ag}_{2} \mathrm{Te}$ nanoparticles and the detection of $\mathrm{Hg}^{2+}$. Zong-Hong Lin: He developed the method to synthesize $\mathrm{Ag}_{2} \mathrm{Te}$ nanoparticles and designed the sensing strategy. Prathik Roy: He gave some advice about synthesis of $\mathrm{Ag}_{2} \mathrm{Te}$ nanoparticles and sensing strategy of $\mathrm{Hg}^{2+}$. Huan-Tsung Chang: He is the advisor of this group.

\section{ACKNOWLEDGMENTS}

This study was supported by the National Science Council of Taiwan under contracts NSC 101-2113-M-002-002-MY3.

Doering, W. E., Piotti, M. E., Natan, M. J., and Freeman, R. G. (2007). SERS as a foundation for nanoscale, optically detected biological labels. Adv. Mater. 19, 3100-3108. doi: 10.1002/adma.200701984

Grubisha, D. S., Lipert, R. J., Park, H.-Y., Driskell, J., and Porter, M. D. (2003). Femtomolar detection of prostate-specific antigen: an immunoassay based on surfaceenhanced Raman scattering and immunogold labels. Anal. Chem. 75, 5936-5943. doi: 10.1021/ac034356f

Han, D., Lim, S. Y., Kim, B. J., Piao, L., and Chung, T. D. (2010). Mercury(II) detection by SERS based on a single gold microshell. Chem. Commun. 46, 5587-5589. doi: 10.1039/C0CC00895H

Huang, C.-C., and Chang, H. T. (2007). Parameters for selective colorimetric sensing of mercury(II) in aqueous solutions using mercaptopropionic acid-modified gold nanoparticles. Chem. Commun. 1215-1217. doi: 10.1039/B615383F

Huang, C.-C., Yang, Z., Lee, K.H., and Chang, H.-T. (2007). Synthesis of highly fluorescent gold nanoparticles for sensing mercury(II). Angew. Chem. Int. Ed. 46, 6824-6828. doi: 10.1002/anie. 200700803

Jena, B. K., and Raj, C. R. (2008) Gold nanoelectrode ensembles for the simultaneous electrochemical detection of ultratrace arsenic, mercury, and copper. Anal. Chem. 80, 4836-4844. doi: 10.1021/ac071064w

Kerker, M. (1987). Estimation of surface-enhanced Raman scattering from surface-averaged electromagnetic intensities. J. Colloid 
Interface Sci. 118, 417-421. doi: 10.1016/0021-9797(87)90477-2

Kneipp, K., Wang, Y., Kneipp, H., Perelman, L. T., Itzkan, I., Dasari, R. R., et al. (1997). Single molecule detection using surface-enhanced Raman scattering (SERS). Phys. Rev. Lett. 78, 1667-1670. doi: 10.1103/PhysRevLett.78.1667

Lee, J.-S., Han, M. S., and Mirkin, C. A. (2007). Colorimetric detection of mercuric ion $\left(\mathrm{Hg}^{2+}\right)$ in aqueous media using DNA-functionalized gold nanoparticles. Angew. Chem. Int. Ed. 46, 4093-4096. doi: 10.1002/anie. 200700269

Leermakers, M., Baeyens, W., Quevauviller, P., and Horvat, M. (2005). Mercury in environmental samples: speciation, artifacts and validation. Trends Anal. Chem. 24, 383-393. doi: 10.1016/j.trac.2004.01.001

Li, Y., Chen, C., Li, B., Sun, J., Wang, J., Gao, Y., et al. (2006). Elimination efficiency of different reagents for the memory effect of mercury using ICP-MS. J. Anal. At. Spectrom. 21, 94-96. doi: 10.1039/B511367A

Lin, Z.-H., and Chang, H.-T. (2008). Preparation of gold-tellurium hybrid nanomaterials for surfaceenhanced Raman spectroscopy. Langmuir 24, 365-367. doi: 10.1021/la702543k

Lin, Z.-H., Chen, I.-C., and Chang, H.-T. (2011). Detection of human serum albumin through surfaceenhanced Raman scattering using gold "pearl necklace" nanomaterials as substrates. Chem. Commun. 47, 7116-7118. doi: 10.1039/C1CC11818H

Luo, Y., Li, K., Wen, G., Liu, Q., Liang, A., and Jiang, Z. (2012). A rapid surface-enhanced Raman scattering method for the determination of trace $\mathrm{Hg}^{2+}$ using rhodamine 6G-aggregated nanosilver as
Probe. Plasmonics 7, 461-468. doi: 10.1007/s11468-012-9329-5

Moon, G. D., Ko, S., Xia, Y., and Jeong, U. (2010). Chemical transformations in ultrathin chalcogenide nanowires. ACS Nano 4, 2307-2319. doi: $10.1021 / \mathrm{nn} 9018575$

Nie, S., and Emery, S. R. (1997). Probing single molecules and single nanoparticles by surfaceenhanced Raman scattering. Science 275, 1102-1106. doi: 10.1126/science.275.5303.1102

Samal, A. K., and Pradeep, T. (2009). Room-temperature chemical synthesis of silver telluride nanowires. J. Phys. Chem. C 113, 13539-13544. doi: 10.1021/jp901953f

Samal, A. K., and Pradeep, T. (2011). Hybrid A-B-A type nanowires through cation exchange. Nanoscale 3, 4840-4847. doi: 10.1039/C1NR11124H

Senapati, T., Senapati, D., Singh, A. K., Fan, Z., Kanchanapally, R., and Ray, P. C. (2011). Highly selective SERS probe for $\mathrm{Hg}$ (II) detection using tryptophanprotected popcorn shaped gold nanoparticles. Chem. Commun. 47, 10326-10328. doi: 10.1039/ C1CC13157E

Stewart, M. E., Anderton, C. R., Thompson, L. B., Maria, J., Gray, S. K., Rogers, J. A., et al. (2008). Nanostructured plasmonic sensors. Chem. Rev. 108, 494-521. doi: $10.1021 / \mathrm{cr} 068126 \mathrm{n}$

Tao, A., Kim, F., Hess, C., Goldberger, J., He, R., Sun, Y., et al. (2003). Langmuir-Blodgett silver nanowire monolayers for molecular sensing using surface-enhanced Raman spectroscopy. Nano Lett. 3, 1229-1233. doi: 10.1021/nl0344209

Wang, D.-S., Chew, H., and Kerker, M. (1980). Enhanced Raman scattering at the surface (SERS) of a spherical particle. Appl. Opt.
19, 2256-2257. doi: 10.1364/AO. 19.002256

Wang, G., Lim, C., Chen, L. Chon, H., Choo, J., Hong, J., et al. (2009). Surface-enhanced Raman scattering in nanoliter droplets: towards high-sensitivity detection of mercury (II) ions. Anal. Bioanal. Chem. 39, 1827-1832. doi: 10.1007/s00216009-2832-7

Wang, H., Wang, Y., Jin, J., and Yang, R. (2008). Gold nanoparticlebased colorimetric and "turn-on" fluorescent probe for mercury(II) ions in aqueous solution. Anal. Chem. 80, 9021-9028. doi: 10.1021/ ac $801382 \mathrm{k}$

Wang, X., Peng, Q., and Li, Y. (2007). Interface-mediated growth of monodispersed nanostructures. Acc. Chem. Res. 40, 635-643. doi: 10.1021/ar600007y

Wang, X., Shen, Y., Xie, A., Li, S., Cai, Y., Wang, Y., et al. (2011). Assembly of dandelion-like Au/PANI nanocomposites and their application as SERS nanosensors. Biosen. Bioelectron. 26, 3063-3067. doi: 10.1016/j.bios.2010.11.044

Xue, X., Wang, F., and Liu, X. (2008). One-step, room temperature, colorimetric detection of mercury $\left(\mathrm{Hg}^{2+}\right)$ using DNA/nanoparticle conjugates. J. Am. Chem. Soc. 130, 3244-3245. doi: 10.1021/ ja076716c

Yang, Y., Shi, J., Tanaka, T., and Nogami, M. (2007). Self-assembled silver nanochains for surfaceenhanced Raman scattering. Langmuir 23, 12042-12047. doi: 10.1021/la701610s

Zahir, F., Rizwi, S. J., Haq, S. K., and Khan, R. H. (2005). Low dose mercury toxicity and human health. Environ. Toxicol. Pharmacol. 20, 351-360. doi: 10.1016/j.etap.2005.03.007
Zamarion, V. M., Timm, R. A., Araki, K., and Toma, H. E. (2008). Ultrasensitive SERS nanoprobes for hazardous metal ions based on trimercaptotriazine-modified gold nanoparticles. Inorg. Chem. 47, 2934-2936. doi: 10.1021/ic800122v

Zhu, Z., Su, Y., Li, J., Li, D., Zhang, J., Song, S., et al. (2009). Highly sensitive electrochemical sensor for mercury(II) ions by using a mercury-specific oligonucleotide probe and gold nanoparticle-based amplification. Anal. Chem. 81, 7660-7666. doi: 10.1021/ac9010809

Conflict of Interest Statement: The authors declare that the research was conducted in the absence of any commercial or financial relationships that could be construed as a potential conflict of interest.

Received: 23 July 2013; paper pending published: 08 August 2013; accepted: 21 September 2013; published online: 09 October 2013.

Citation: Wang C-W, Lin Z-H, Roy $P$ and Chang H-T (2013) Detection of mercury ions using silver telluride nanoparticles as a substrate and recognition element through surface-enhanced Raman scattering. Front. Chem. 1:20. doi: 10.3389/fchem.2013.00020

This article was submitted to Analytical Chemistry, a section of the journal Frontiers in Chemistry.

Copyright (c) 2013 Wang, Lin, Roy and Chang. This is an open-access article distributed under the terms of the Creative Commons Attribution License (CC BY). The use, distribution or reproduction in other forums is permitted, provided the original author(s) or licensor are credited and that the original publication in this journal is cited, in accordance with accepted academic practice. No use, distribution or reproduction is permitted which does not comply with these terms. 